\title{
Duane retraction syndrome: causes, effects and management strategies
}

This article was published in the following Dove Press journal:

Clinical Ophthalmology

30 October 2017

Number of times this article has been viewed

\section{Ramesh Kekunnaya \\ Mithila Negalur}

Pediatric Ophthalmology and Strabismus Services, Child Sight Institute, Jasti $\vee$ Ramannama

Children's Eye Care Center, KAR

Campus, Hyderabad, India
Correspondence: Ramesh Kekunnaya Child Sight Institute, Jasti V Ramanamma Children's Eye Care Center, Pediatric Ophthalmology, Strabismus and Neuroophthalmology, LV Prasad Eye Hospital, Kallam Anji Reddy Campus, Hyderabad 500034, India

Tel +9| $40306 \mid 2632$

Fax +9l 402354 827|

Email rameshak@lvpei.org

\begin{abstract}
Duane retraction syndrome (DRS) is a congenital eye movement anomaly characterized by variable horizontal duction deficits, with narrowing of the palpebral fissure and globe retraction on attempted adduction, occasionally accompanied by upshoot or downshoot. The etiopathogenesis of this condition can be explained by a spectrum of mechanical, innervational, neurologic and genetic abnormalities occurring independently or which influence each other giving rise to patterns of clinical presentations along with a complex set of ocular and systemic anomalies. Huber type I DRS is the most common form of DRS with an earlier presentation, while Huber type II is the least common presentation. Usually, patients with unilateral type I Duane syndrome have esotropia more frequently than exotropia, those with type II have exotropia and those with type III have esotropia and exotropia occurring equally common. Cases of bilateral DRS may have variable presentation depending upon the type of presentation in each eye. As regards its management, DRS classification based on primary position deviation as esotropic, exotropic or orthotropic is more relevant than Huber's classification before planning surgery. Surgical approach to these patients is challenging and must be individualized based on the amount of ocular deviation, abnormal head position, associated globe retraction and overshoots.
\end{abstract}

Keywords: Duane syndrome, strabismus surgery, esotropia, overshoots

\section{Introduction}

Duane retraction syndrome (DRS), also known as Stilling-Turk-Duane syndrome, is a congenital eye movement anomaly characterized by variable horizontal duction deficits, with narrowing of the palpebral fissure and globe retraction on attempted adduction, occasionally accompanied by upshoot or downshoot. ${ }^{1}$ Though DRS represents $<5 \%$ of all forms of strabismus, ${ }^{2,3}$ it was widely described in the literature as early as the 19th century. In 1879, Heuck $^{4}$ first reported a patient with congenitally anomalous eye movements and globe retraction in adduction. Later, Sinclair ${ }^{5}$ (1895), Bahr $^{6}$ (1896), Stilling and Bergmann ${ }^{7}$ (1887), Turk $^{8}$ (1899) and several other authors ${ }^{9}$ went on to describe this entity in greater detail. It was in 1905 that Alexander Duane ${ }^{1}$ reported a series of 54 cases with DRS, giving a detailed description of its clinical features and summarizing the possible etiopathogenesis and management of this syndrome.

Decades later, with the advent of neuroimaging, muscle electrophysiology and genetic analysis, there has been greater understanding of this form of strabismus, now considered a congenital cranial dysinnervation disorder (CCDD), giving better insights into the management of this challenging syndrome.

\section{Etiology of DRS}

Various theories were proposed to explain the etiology of DRS. 


\section{Historical aspect}

\section{Mechanical anomalies}

Turk $^{8}$ first attempted to explain the cause of globe retraction in DRS, attributing it to an abnormally tight lateral rectus (LR), which was found to behave as an "inelastic band". Wolff similarly described a congenitally anomalous LR, which was inelastic and tight to be the cause of abnormal motility in DRS. On the other hand, a developmental anomaly leading to a tight LR due to nuclear aplasia or birth trauma was also proposed later. ${ }^{10}$

Another theory put forth was the presence of dual insertion $^{6,11}$ of the medial rectus (MR) muscle, one which rotated the globe and the other one anomalous insertion located posteriorly which retracted the globe. This was well accepted for a long time until lack of this finding intraoperatively in most of the cases made it questionable.

\section{Innervational anomalies}

Possibility of an underlying innervational etiology came into light when Breinin ${ }^{12}$ studied the electric potentials generated by muscles in various positions of gaze in DRS. He found that there was no LR activity recordable in attempted abduction, while maximum LR action potentials were generated in adduction, suggesting that the LR was receiving innervation in adduction. This was thought to be the cause of co-contraction and globe retraction. Few others ${ }^{13,14}$ also studied these muscle potentials and found variable degrees of LR potentials from abduction to adduction along with abnormal responses in vertical and oblique gazes. The MR muscle in all these was found to be normal. Strachan and Brown ${ }^{15}$ quantified this paradoxical innervations using electromyography. They found variable LR activity depending on the position of gaze, while MR spikes were almost always consistent. Occasionally, synergistic innervation between MR and the vertical rectus muscles and obliques was noted. These findings were further confirmed by Metz ${ }^{16}$ who studied the saccadic velocities of eye movements in DRS. The author noted slowing of abduction saccades due to lack of normal LR innervations, along with slowing of adduction saccades, possibly due to paradoxical innervation.

\section{Central nervous system anomalies}

Understanding muscle electrophysiology in DRS made it evident that the causative etiology was absent normal sixth nerve innervation to the LR, either nuclear (eg, anomalous innervation by the oculomotor nerve) or supranuclear (eg, brainstem abnormality) in origin.
While some authors have found abducens nucleus hypoplasia ${ }^{17}$ or complete absence ${ }^{18}$ in the brain stem to be the cause of DRS, others ${ }^{19}$ have proposed that infranuclear abnormalities at the level of cavernous sinus, where the oculomotor and abducens nerves are in vicinity of each other, lead to features of DRS. These early attempts to understand the neurologic basis of DRS were only based on autopsy studies.

Further evidence to support the role of neurologic anomalies in DRS is the presence of synkinesis, ${ }^{20}$ which is occasionally seen with DRS, for example, Marcus Gunn Jaw Winking phenomenon, crocodile tears etc. Also, it has been suggested that unilateral abducting nystagmus in the normal eye of DRS patients is a marker of brainstem abnormality indicative of a central neurologic anomaly. ${ }^{21}$

\section{Newer concepts}

It was in 1998 that Parsa et $\mathrm{al}^{22}$ demonstrated the absence of left sixth nerve in a case of unilateral DRS using highresolution T1-weighted images on magnetic resonance imaging (MRI). This congenital absence of innervation to the muscles has been found to cause fibrotic changes in the extraocular muscles leading to abnormal motility in DRS, a concept which has evolved over the last decade to be known as CCDD. ${ }^{23}$ In this case, developmental abnormalities of one or more cranial nerves cause congenital dysinnervation of the cranial muscles. This may be primary due to absence of normal innervation or secondary following aberrant innervations from other cranial nerves. CCDD is a nonprogressive entity and may also have associated bony abnormalities. $^{24}$

\section{The role of genetics in the development of DRS}

Congenital strabismus, in general, may be a sporadic condition or the result of mutations in genes such as $P H O X 2 A,{ }^{25}$ $H O X A 1^{26}$ and $R O B 03^{27}$, which are necessary for the growth and maturation of brainstem motor neurons and axons.

DRS has been commonly found to be a sporadic disorder, but in $10 \%$ of cases, it may be familial, which includes an autosomal dominant mode of inheritance in associated syndromes. ${ }^{28}$ Genetic analysis of the autosomal dominant variant has been found to be associated with mutations in the CHN1 gene. This gene mutation is said to affect the abducens (and less commonly, the oculomotor) nerve. ${ }^{29}$ In cases with isolated DRS without any other systemic associations, the DURS1 locus on chromosome 2q31 has been identified and mapped. This was studied by the analysis of 
a dominant DRS pedigree. ${ }^{30}$ In DRS with associated malformation syndromes, the Duane radial ray syndrome has been found to have a dominant inheritance with incomplete penetrance. This syndrome has been mapped to heterozygous nonsense frameshift and deletion mutations in SALL4 gene on chromosome $20 .^{31,32}$

Other syndromes associated with this gene include Holt-Oram and acro-renal-ocular syndromes. ${ }^{33}$ Additional association of DRS includes the Bosley-Salih-Alorainy syndrome (bilateral DRS with inner ear malformations, cerebrovascular and cognitive abnormalities) in which there is an autosomal recessive inheritance and has been mapped to chromosome 7p15.2 of the HOXA gene. ${ }^{26}$

Studying the genetics of DRS in monozygotic twins has revealed both the following presentations - some reporting concordance for DRS, while others were found to be discordant for DRS. In monozygotic twins who had unilateral DRS, commonly, a pattern was also noted wherein each twin had the opposite eye affected known as "mirror images". ${ }^{34}$ This could be explained by the hypothesis that there were certain genes with incomplete penetrance and variable expression influenced by various stimuli during embryogenesis. These finally determined the laterality and presentation of DRS.

Patients with sporadic DRS have also been found to have associated congenital malformations. Pfaffenbach and $\operatorname{Cross}^{35}$ studied these anomalies which were skeletal, auricular, ocular or neural in presentation. Generally, the crucial time for development of these congenital malformations was found to be around the fourth to eighth week of gestation. Similarly, patients with thalidomide embryopathy having DRS were also found to be associated with maternal exposure around a similar time period. These findings suggested that there could be a critical period during embryogenesis, in which an insult could result in various congenital malformations including DRS. ${ }^{36}$

\section{Pathogenesis}

The preceding discussion shows that DRS is a group of entities linked by dysinnervation leading to limited horizontal gaze and globe retraction in attempted adduction. Understanding these mechanisms can help understand the pathogenesis of the presenting features of this syndrome.

Globe retraction in adduction, which is a characteristic feature of DRS, is found to be due to tight fibrotic muscles, sometimes with anomalous insertions. Usually, these changes have been observed in the horizontal rectus muscles, as is often noted while operating such patients. ${ }^{37}$ Sometimes, abnormal muscle slips or foot plates attaching to the sclera are noted after disinsertion of muscles intraoperatively. These have been noted commonly in the LR and very rarely in the MR. Unless these muscle slips are released, the tightness on forced ductions remains. Second, paradoxical innervation leading to co-contraction of MR along with LR, as described by Scott, was found to contribute to globe retraction in attempted adduction. ${ }^{18,38}$

The pathogenesis of upshoots and downshoots (Figure 1) in DRS can be explained by these mechanical factors as well as certain innervational anomalies. The mechanical cause of these vertical movements is described as due to a "bridle effect" 39 of the tight LR, also known as the "leash effect". ${ }^{40}$ As the globe adducts and moves above or below the horizontal plane, there is sudden slippage of the tight LR, causing an upshoot or downshoot. In severe cases, this has been described to manifest even with the slightest of movement in adduction, known as "knife edge effect". ${ }^{40}$ These tight muscles can even give rise to an alphabet pattern of strabismus. These mechanical upshoots and downshoots in DRS are characterized by a sudden abrupt movement following a small vertical movement in adduction and usually do not have primary gaze vertical tropia.

In contrast to this, another type of vertical movement is noted in DRS, wherein there is a gradual vertical movement (elevation or depression) of the eye as it turns from abduction to adduction. This type of eye movement has been found to be due to anomalous paradoxical innervations of the LR by the oculomotor nerve. Such cases may even have vertical tropia in the primary position, and these are termed as innervational upshoots and downshoots. ${ }^{18,36}$

Thus, DRS is a spectrum of mechanical, innervational, neurologic and genetic abnormalities that influence each other giving rise to patterns of clinical presentations which can be categorized as described below.

\section{Classification of DRS}

Various systems of classification were proposed to understand the mechanism and presentation of DRS, as described in Table 1 .
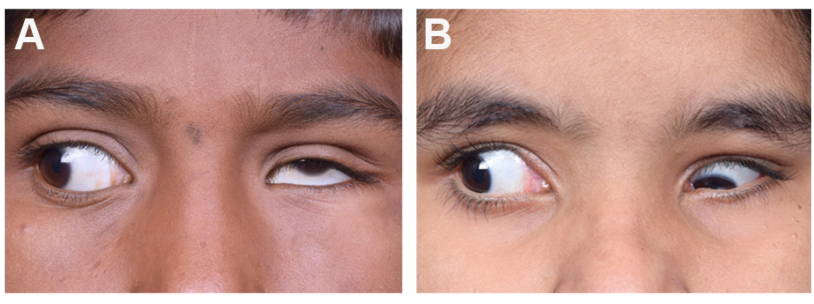

Figure I Demonstrating an upshoot $(\mathbf{A})$ and downshoot $(\mathbf{B})$ on attempted adduction. 
Table I Classification of DRS

\begin{tabular}{|c|c|c|}
\hline $\begin{array}{l}\text { Classification } \\
\text { system }\end{array}$ & Basis of classification & \\
\hline \multirow[t]{4}{*}{ Papst $^{41-43}$} & Abnormal co-contraction & I. MR and $L R$ \\
\hline & & 2. Superior rectus and LR \\
\hline & & 3. Inferior rectus and LR \\
\hline & & 4. LR and other muscles \\
\hline \multirow[t]{3}{*}{ Malbran ${ }^{44}$} & Motility & Type I: Palsy of abduction \\
\hline & & Type II: Palsy of adduction \\
\hline & & Type III: Limitation of depression and elevation without impairment of horizontal movements \\
\hline \multirow{4}{*}{$\begin{array}{l}\text { Lyle and } \\
\text { Bridgeman }\end{array}$} & Motility & Type A: Abduction more deficient than adduction, but both are deficient. Adduction causes globe \\
\hline & & retraction and palpebral fissure narrowing \\
\hline & & Type B: Abduction is deficient, but not adduction \\
\hline & & $\begin{array}{l}\text { Type C: Abduction less deficient than adduction, but both are deficient. Adduction causes globe } \\
\text { retraction and palpebral fissure narrowing }\end{array}$ \\
\hline \multirow[t]{11}{*}{ Huber ${ }^{46}$} & EMG & $\begin{array}{l}\text { Type I (70\%-80\%): Marked limitation of abduction with minimally defective or normal adduction, globe } \\
\text { retraction and palpebral fissure narrowing in adduction, widening in abduction }\end{array}$ \\
\hline & & EMG recordings showed paradoxical innervations of the LR with maximum impulses on adduction and \\
\hline & & defective impulses in attempted abduction. MR was found to have normal electric behavior \\
\hline & & Type II (7\%): Marked limitation of adduction with primary position exotropia of the affected \\
\hline & & $\begin{array}{l}\text { eye, abduction normal or slightly limited with globe retraction and palpebral fissure narrowing in } \\
\text { attempted adduction }\end{array}$ \\
\hline & & On EMG, LR showed peak impulses on abduction and a second paradoxical impulse on attempted \\
\hline & & adduction, while the electrical activity of MR was normal \\
\hline & & $\begin{array}{l}\text { Type III (I5\%): Limitation or complete absence of adduction and abduction with globe retraction and } \\
\text { palpebral fissure narrowing in attempted adduction }\end{array}$ \\
\hline & & EMG showed simultaneous innervation of $L R$ and $M R$ muscles in primary gaze, adduction and abduction \\
\hline & & Huber also went on to describe the alphabet patterns of strabismus, which are also seen in DRS, \\
\hline & & suggesting that there are groups of patients wherein the vertical rectus has this synergistic innervation \\
\hline
\end{tabular}

Abbreviations: DRS, Duane retraction syndrome; EMG, electromyography; LR, lateral rectus; MR, medial rectus.

Ahluwalia et $\mathrm{l}^{47}$ modified Huber's classification to include further subgroups in each category described by Huber. Depending upon the alignment in primary gaze, each Huber type was divided into A, B and C, indicating esotropia, exotropia and orthophoria, respectively, thus making it even more relevant clinically and surgically.

\section{Demography}

As discussed earlier, DRS represents about $1 \%-5 \%$ of all forms of strabismus. ${ }^{2,3}$

It is usually a sporadic entity ( $80 \%$ cases) commonly affecting females, though familial cases have also been noted in $5 \%-10 \%$ of patients. ${ }^{48} \mathrm{DRS}$ is also more commonly unilateral than bilateral, affecting the left eye more often. ${ }^{49-51}$ Bilateral cases of DRS have been reported to range from $10 \%$ to $24 \%$ of all DRS cases presenting to the clinic., $2,52,53$ In both unilateral and bilateral DRS, type I is the most common presentation, followed by types III and II, respectively. Some bilateral cases have been reported to have type I in one eye and type II in the other. ${ }^{47} \mathrm{~A}$ female preponderance is noted (up to 60\%), especially in unilateral type I DRS. Except for one study by Tredici and von Noorden ${ }^{54}$ in which only $40 \%$ of cases were females, most others reported a higher incidence in females. Some studies ${ }^{48,55}$ have found DRS types II and III also to be more prevalent in females compared to males. Bilateral DRS, on the other hand, may be seen more often in males, but no predilection is noted. ${ }^{49,50}$

It is postulated that females are more susceptible to the expression of genes responsible for manifestation of DRS, as these are partly sex limited with incomplete penetrance. ${ }^{45,51}$

Another explanation put forth by Parsa and Robert ${ }^{56}$ states that during embryogenesis, higher estrogen levels along with greater risk of inflammation predispose females to venous thromboembolic events. This along with right to left shunt causes more embolic phenomena that affect the left carotid artery, causing dysregulated apoptosis followed by misinnervation and ocular malformations. This predilection for the left eye is noted most often in types I and III DRS and is uncommon in type II. ${ }^{47,48}$

Also, some authors ${ }^{45}$ have noted evidence for a subclinical or "forme fruste" variant of DRS in the family members of the affected patient. These individuals may show extraocular muscle paresis (other than LR) or minimal palpebral fissure size changes during horizontal ductions. Miyake et al, ${ }^{57}$ 
in their study, analyzed a family with c.443A $>\mathrm{T}$ CHN1 heterozygous missense mutation in a dominant pattern among five members with congenital ocular dysmotility.

Apart from DRS in two members, other phenotypes included vertical strabismus with elevation deficits. Thus, CHN1 mutations may have varied presentation and should be considered in the differential diagnosis of patients with elevation deficits, even in the absence of DRS.

\section{Clinical presentation}

Common reasons for seeking medical attention in DRS include an abnormal head position of the child, one of the eyes appearing smaller than the other due to globe retraction, pseudoptosis in adduction or abnormal eye movements. Though DRS is present at birth, in the early stages, it may appear only as an abduction deficit. As LR inelasticity and tightness develops with time, globe retraction and limitation of motility may be more pronounced. ${ }^{58}$

Often, parents mistake abduction deficiency of the affected eye to be esotropia of the contralateral eye when the child looks toward the affected side. This occurs due to overadduction of the uninvolved eye due to Hering's law. ${ }^{59}$

Thus, it is important to explain to the parents and, if necessary, the pediatrician regarding the involved eye and discuss the presentation of DRS, so that is not mistaken for abducens nerve palsy, which may have serious neurologic implications.

\section{Clinical features}

A. Age - Despite being a congenital anomaly, patients may not always report to the clinics early. Age at presentation is variable and has been found to be younger in type I DRS, possibly due to earlier presentation to the pediatrician or pediatric ophthalmologist. In a series of 441 cases of DRS by Kekunnaya et al, ${ }^{50}$ the mean age at presentation in unilateral types I, II and III, and bilateral DRS was found to be $13.5 \pm 13.46,23.00 \pm 15.62,21.93 \pm 13.04$ and $12.40 \pm 10.30$ years, respectively. No significant age difference has been found in unilateral or bilateral cases and types II and III DRS. The variations in literature are probably due to variable age of presentation in the clinics.

1. Refractive error and amblyopia - Considering refractive status, about $30 \%-80 \%$ of DRS patients have been shown to have hypermetropia or hypermetropic astigmatism greater than +1.50 Diopters (D) sphere, some even more than +4.00 DS. These cases, especially with high hyperopia, may have an associated accommodative component, which must be taken into account despite not being directly linked to the underlying etiology of DRS. ${ }^{60}$ Hence, there is a need for cycloplegic refraction in all cases of DRS.

2. Myopia, simple myopic astigmatism and emmetropia are less common and are found to be almost equally distributed. ${ }^{44,47,51,61}$ Variable incidence of anisometropia has been noted in literature. Kirkham ${ }^{61}$ found anisometropia $>1 \mathrm{D}$ in about $40 \%$ of cases, while Tredici and von Noorden ${ }^{54}$ reported an average incidence of only 3\%. Anisometropic and ametropic amblyopia has been reported to be the commonest cause of amblyopia in DRS, especially unilateral type $\mathrm{I}, 2,47,48$ though O'Malley et $\mathrm{al}^{55}$ found strabismic amblyopia to be the commonest cause. Less frequently, stimulus deprivation and mixed mechanisms of amblyopia have been seen.

3. Strabismus evaluation - A review of literature ${ }^{1,44,62-64}$ shows that Huber type I DRS is the most common form of DRS, while type II is the least common presentation.

Also, esotropia is found to be the most common primary position deviation, followed by orthotropia, though some studies report otherwise. Usually, patients with unilateral type I Duane syndrome have esotropia more frequently than exotropia, those with type II have exotropia and those with type III have esotropia, exotropia and orthotropia occurring equally common. ${ }^{63}$ Primary position deviation in cases of bilateral DRS is found to be variable depending upon the type of presentation in each eye.

B. Motor evaluation of strabismus

1. Motility - One of the most notable features of DRS is the abduction limitation. The abduction deficit in DRS accompanies a disproportionately smaller primary position deviation. This helps to distinguish it from a sixth nerve palsy, where the primary deviation and the abduction limitation are in proportion to each other. ${ }^{59}$ This is most likely due to an underlying adduction deficit, which is present in varying amounts in DRS. This adduction deficit is evident from the fact that DRS patients have a remote near point of convergence. Also, these patients can be shown to have exotropia in the gaze opposite to the affected eye due to this adduction deficit.

2. Deviations - As discussed earlier, esotropia is the most common deviation in primary position in DRS. Measuring the deviation accurately requires the head to be in forced primary position while performing the 
cover test, as these patients have a strong tendency for abnormal head postures which may be very small as well. In this position, the secondary deviation is greater than the primary deviation in DRS. Also, one must remember to measure the deviations in the lateral and vertical gazes due to varying amounts of esotropia and exotropia in the lateral gazes caused by the motility deficits. In case the abduction and adduction limitations are almost equal to each other, there may be orthotropia in the primary gaze; otherwise, the predominant deficiency will determine the type of DRS and primary gaze measurement. By performing the cover test in up and down gazes, one may note any pattern strabismus. Bilateral DRS may be more likely to have pattern strabismus, compared to unilateral cases. ${ }^{65} \mathrm{~V}$ pattern strabismus may be commonly seen in DRS, and sometimes an A pattern may also be noted, especially in cases of bilateral DRS. Hence, an A pattern must alert the clinician to look for bilateral DRS. Sometimes, with the presence of upshoot and downshoot, an X pattern may be seen.

3. Anomalous vertical movements and globe retractionUpshoot and downshoot are abnormal vertical eye movements frequently seen in cases of DRS. As discussed earlier, these may be due to mechanical or innervational anomalies. A patient may have both upshoot and downshoot, depending on whether the eye is moving slightly up or down during adduction and, in some cases, may have hyper- or hypotropia in the primary position itself. Kekunnaya et $\mathrm{al}^{50}$ have reported an incidence of upshoot or downshoot in $43 \%$ of their cases. They found these movements to be more common in unilateral DRS types I and III, unlike Mohan et $\mathrm{al}^{51}$ who found the incidence to be significantly greater in type III. In this study, Mohan et al have found the mechanical type to be more common than the innervational type ( $26 \%$ vs $12 \%)$. They also found a statistically significant association between exotropic DRS and mechanical upshoots and primary position vertical tropia with innervational upshoots. ${ }^{66}$ Globe retraction occurs due to the co-contraction of the extraocular muscles, which is more pronounced in attempted adduction. This is accompanied by changes in the palpebral fissure, which are not merely passive changes. In the study by Isenberg and Urist, ${ }^{63}$ they found that there is drooping of upper lid along with elevation of lower lid in about $52 \%$ of cases of DRS. In $18 \%$, only upper lid changes were noted, while $21 \%$ had only lower lid elevation. A small proportion of cases $(7 \%)$ did not show any lid changes with motility in DRS. In 2016, Kekunnaya et al ${ }^{67}$ published a novel clinical grading system for globe retraction and overshoots to objectively quantify these. They excluded bilateral cases, cases with atypical features and vertical deviations.

- Grading for globe retraction: With the involved eye in the maximum adducted position, a scale is used at the center of the palpebral fissure width to measure the palpebral aperture height and compared with that of the fellow eye in abduction.

0 No narrowing

$1<25 \%$

$225 \%-<50 \%$

$350 \%-<75 \%$

$4 \geq 75 \%$

- Grading for overshoots: With the involved eye in adducted position, a straight line parallel to the intermedial canthal line is drawn from the pupillary center of the fellow eye.

0 Line bisects the pupil of involved eye.

1 Line lies between the pupillary center and the pupillary margin.

2 Line lies between the pupillary margin and the limbus.

3 Line lies at the limbus or over the sclera.

4 Cornea disappears below the lid (pumpkin seed sign).

Figure 2 shows various grades of retraction and overshoot.
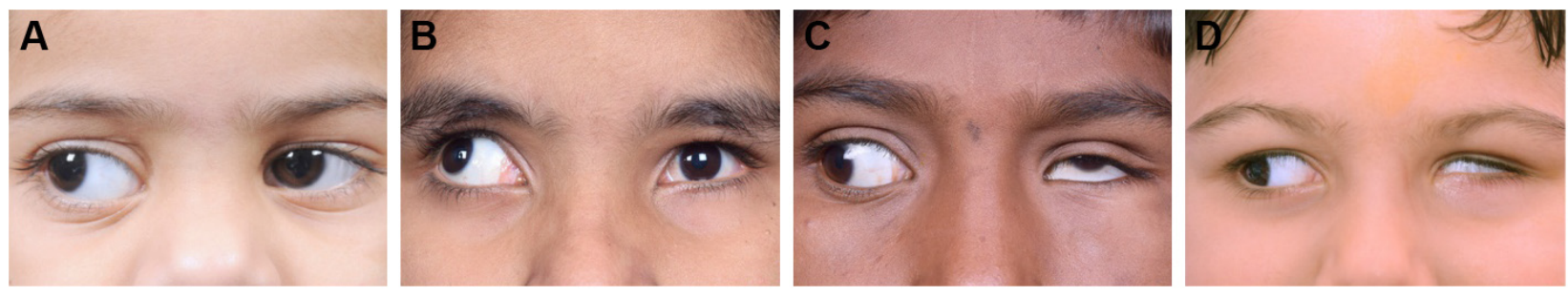

Figure 2 Clinical grading system for globe retraction and overshoots.

Notes: (A) Grade I retraction and upshoot; (B) grade 2 retraction; (C) grade 3 retraction and upshoot; (D) grade 4 retraction and upshoot (pumpkin seed sign). 
4. Head posture - Head turns are very commonly seen in DRS, especially unilateral cases in both esotropic and exotropic types. This can be objectively assessed in the clinic using a goniometer. The aim of the head turn is to maintain binocular single vision and make up for the duction deficit, depending on which duction is maximally affected. Some authors ${ }^{68}$ report head turn in orthotropic DRS also, which may be to avoid the discomfort of sudden anomalous vertical eye movements. Kekunnaya et al, ${ }^{50}$ in their study, were the first to report a significantly lower incidence of head turn in type II DRS, compared to types I and III.

5. Bilateral vs unilateral DRS - As described previously in the literature, bilateral DRS is less frequently seen than unilateral ones, with a reported incidence between $10 \%$ and $24 \%$. Also, bilateral type I DRS has been found to be the most common type of presentation. ${ }^{50-52,69}$ Zanin et $\mathrm{al}^{70}$ have classified bilateral DRS into three types in agreement with Jampolsky, ${ }^{71}$ based on the functional prognosis:

- Bilateral DRS with fusion - usually bilateral type I with small angle of deviation or orthotropia and very minimal head posture, if any;

- Bilateral DRS without fusion - prominent eso- or exodeviation and

- Bilateral DRS with an alphabet pattern.

In this study, ${ }^{70}$ the bilateral form of Duane syndrome was more likely to be associated with low visual acuity, lesser tendencies for abnormal head posture, high incidence of $\mathrm{A}$ and $\mathrm{V}$ patterns and associated congenital anomalies. The low visual acuity in bilateral DRS, also noted by Isenberg and Urist, ${ }^{63}$ could be due to ametropia, anisometropia and a higher prevalence of vertical strabismus in these patients. A low incidence of abnormal head posture in bilateral Duane syndrome has been mentioned in the literature only by Raab. ${ }^{6}$ This may possibly be due to symmetrical limitation of motility not requiring any head turn, or there may be very severe retraction and complex anomalous movements, which preclude normal fusion with any abnormal head posture.

C. Sensory evaluation of strabismus

As described previously, DRS patients try to maintain fusion with an appropriate head turn whenever possible and rarely complain of diplopia. If present, these patients have been found to ignore the second image rather than suppressing it. Hence, many cases of DRS have been found to have good stereopsis when measured in clinics. ${ }^{2}$

D. Other variants of DRS

a. Vertical retraction syndrome: This is a very rare clinical entity first reported in Chinese literature.
It consists of variable amounts of limitation of elevation or depression with globe retraction and palpebral fissure narrowing. The affected eye may be orthotropic, hypertropic or hypotropic in the primary position and may coexist with horizontal retraction. This vertical retraction may be due to innervational anomalies, fibrosis of vertical rectus muscles or a "tethering" effect of the horizontal rectus. ${ }^{72}$

b. Congenital adduction deficit with synergistic divergence: This is another rare variant of DRS presenting with unilateral adduction deficit and simultaneous abduction of the eye on attempted adduction. ${ }^{73}$ It may be associated with a head turn to uninvolved side, large angle exotropia, along with an abducting nystagmus on attempted adduction. This is sometimes considered to be a variant of Huber type II DRS. In some cases, it may be iatrogenically induced, called as iatrogenic simultaneous abduction or "ocular splits" $" 74$ in cases where large LR resections have been performed.

E. Associations of DRS - DRS is found to be associated with numerous congenital anomalies, both ocular and nonocular as listed in Table 2.

F. Acquired retraction syndrome - Duane et $\mathrm{al}^{82}$ went on to describe an entity called acquired retraction syndrome or pseudoduane syndrome. These patients present with limitation of abduction along with globe retraction in abduction. They usually have history of some kind if trauma, systemic illness and diplopia, differentiating it from true DRS. The causes of acquired retraction syndrome are as enlisted in Table 3.

\section{Other functions}

Although intelligence is usually normal in DRS, intellectual disability has been reported in a few cases of DRS with borderline intelligence and cases of autism spectrum disorder associated with fetal thalidomide exposure or HOXA1related syndromes. ${ }^{92,93}$

\section{Management of DRS}

Management of DRS is a challenge, and surgeons worldwide have their own preferred practices. In general, the surgical plan and aim of strabismus surgery in DRS is usually based on the following:

1. Primary position deviation

2. Degree of abnormal head posture

3. Severity of globe retraction and overshoots

4. Degree of limitation of ductions

5. Forced duction testing (FDT) 
Table 2 Ocular and systemic associations of DRS

\begin{tabular}{|c|c|c|c|c|}
\hline External examination & $\begin{array}{l}\text { Anterior } \\
\text { segment }\end{array}$ & $\begin{array}{l}\text { Posterior } \\
\text { segment }\end{array}$ & $\begin{array}{l}\text { Nonocular } \\
\text { associations }^{29-32,79-81}\end{array}$ & $\begin{array}{l}\text { Associated } \\
\text { syndromes }^{79-81}\end{array}$ \\
\hline Ptosis & $\begin{array}{l}\text { Epibulbar } \\
\text { dermoid }\end{array}$ & Coloboma $^{78}$ & $\begin{array}{l}\text { Preauricular tags, pinna } \\
\text { defects, deafness }\end{array}$ & Goldenhar \\
\hline Marcus-Gunn Jaw Wink & Microcornea $^{76}$ & $\begin{array}{l}\text { Optic nerve } \\
\text { hypoplasia }\end{array}$ & $\begin{array}{l}\text { Cleft palate, facial } \\
\text { asymmetry }\end{array}$ & Klippel-Feil \\
\hline Horner's syndrome ${ }^{64}$ & Keratoconus $^{76}$ & Morning glory disc & Cardiac anomalies & Holt-Oram \\
\hline Nystagmus & Coloboma $^{78}$ & Myelinated nerves ${ }^{35}$ & $\begin{array}{l}\text { Limb deformities, } \\
\text { phocomelia }\end{array}$ & Wildervanck \\
\hline $\begin{array}{l}\text { Microphthalmos, }{ }^{35} \text { posterior } \\
\text { microphthalmos }{ }^{75}\end{array}$ & Cataract & Staphyloma ${ }^{35}$ & $\begin{array}{l}\text { Vertebral anomalies } \\
\text { spina bifida }\end{array}$ & $\begin{array}{l}\text { Arthrogryposis } \\
\text { multiplex congenital }\end{array}$ \\
\hline Brown syndrome ${ }^{76}$ & & Situs inversus disc ${ }^{35}$ & $\begin{array}{l}\text { Renal dysplasia, } \\
\text { vesicoureteral reflux, } \\
\text { imperforate anus }\end{array}$ & $\begin{array}{l}\text { Oculocutaneous } \\
\text { albinism }\end{array}$ \\
\hline $\begin{array}{l}\text { Familial external } \\
\text { ophthalmoplegia }^{77}\end{array}$ & & $\begin{array}{l}\text { Persistent fetal } \\
\text { vasculature }\end{array}$ & Microcephaly & $\begin{array}{l}\text { Fetal alcohol } \\
\text { syndrome }\end{array}$ \\
\hline
\end{tabular}

Abbreviation: DRS, Duane retraction syndrome.

6. Extent of field of binocular single vision

DRS classification based on primary position deviation as esotropic, exotropic or orthotropic is said to be more relevant than Huber's classification before planning surgery.

\section{Esotropic DRS}

In cases of esotropic DRS, various surgical procedures may be considered, but any coexisting accommodative component must be first corrected by prescribing spectacles preoperatively to avoid consecutive exotropia. Sometimes, even the abnormal head posture may improve upon treating with spectacles. ${ }^{60}$

MR recession should be considered in situations with tight MR on intraoperative FDT. Unilateral MR recession is very commonly practiced in such cases and can correct up to 20 prism diopters (PD) of esotropia. ${ }^{94,95}$ However, in cases with accommodative or partially accommodative esotropia, the MR recession should be planned after measuring the deviation with hyperopic glasses to prevent overcorrection. Also, one needs to look for anomalous muscle bands in cases of very tight FDT.

Table 3 Acquired retraction syndrome mechanical causes

\begin{tabular}{|l|l|}
\hline Mechanical causes & Trauma $^{82}$ and orbital fracture \\
\hline & ${\text { Bony } \text { orbital metastasis }^{84}}^{84}$ mall) \\
\hline & Orbital inflammation \\
\hline & Orbital surgery \\
\hline & Thyroid myopathy \\
\hline & Conjunctival surgery causing scarring \\
\hline & Head injury \\
\hline Neurogenic causes & Intracranial surgery \\
\hline & $\begin{array}{l}\text { Brainstem tumors such as glioma and skull } \\
\text { base meningioma }\end{array}$ \\
\hline
\end{tabular}

Apart from improving primary position deviation, MR recession may also improve abduction of the affected eye if there was some prior lateral movement beyond the midline, thereby expanding binocular field of single vision. Various authors believe in performing MR recession no more than $6 \mathrm{~mm}$ or sometimes $5 \mathrm{~mm}$, lest there be an induced adduction deficit creating an exotropia in contralateral gaze.

Sometimes, a large contralateral MR recession may be performed to match the abduction deficit of the affected eye and improve the binocular field of vision toward the affected side. This is a useful technique in cases where the abduction limitation is -2 or better. ${ }^{96}$

However, surgeons must be careful with recessions of the contralateral MR muscle in patients with severe anomalous co-contraction. This may lead by Hering's law to a severe co-contraction of the anomalous LR muscle in attempted rotation toward the affected gaze. Another risk here is the possibility of inducing a vertical deviation in patients with vertical dysinnervation.

On certain occasions, MR recession can also be performed as an initial procedure, followed by vertical rectus transposition as a second-stage procedure if necessary.

Bilateral MR recessions may also be required in some situations. First, in cases of esotropia with primary position deviation $>20 \mathrm{PD}$, single MR recession of $\leq 6 \mathrm{~mm}$ is unlikely to be sufficient. Hence, here, bilateral MR recessions not exceeding 5-6 mm may be done.

Second, in cases with severe globe retraction, along with MR, LR may have to be recessed, thereby actually increasing the esotropia. Recessing the contralateral MR in such cases may also help to correct the total esotropia. 
Lastly, bilateral MR recession may also help prevent contracture of the MR on the affected side by creating "fixation duress" in the contralateral eye. After surgery, MR of the fixing eye receives increased innervation to maintain fixation, which reduces innervation to its LR. This, in turn, reduces the innervational tone of the MR of the affected eye, lowering the risk of its contracture. This effect is said to be different from the aforementioned mechanism of matching duction deficit, and at least $7-8 \mathrm{~mm}$ of contralateral MR recession is necessary for it to act. ${ }^{73}$

In certain cases, when esotropia is at least $25 \mathrm{PD}$ with normal adduction and significantly limited abduction, MR recession can be combined with LR resection. This procedure is suitable in the absence of severe globe retraction and upshoots or downshoots. Kraft, ${ }^{97}$ in his study, has recommended resecting the LR by not more than 3-3.5 mm and recessing MR not more than $5 \mathrm{~mm}$ in these patients. He found that with this approach, the adduction deficit induced in the DRS eye was less than that with bi-MR recessions, though both achieved a significant improvement in esotropia and abduction.

Cases with bilateral esotropic DRS, which is the commonest presentation, ${ }^{47}$ are most often corrected by bilateral MR recessions, depending on the primary position deviation, muscle tightness and limitation of ductions. Sachdeva et $\mathrm{a}^{98}$ studied 14 patients with bilateral esotropic DRS and found $86 \%$ success rate with a mean surgical dose of $5.6 \mathrm{~mm}$ (range being 5-7 $\mathrm{mm}$ ) for bi-MR recessions. The mean preoperative esotropia in this series was $38 \mathrm{PD}$, with none of the patients developing significant postoperative adduction limitation.

Another technique to correct the eso-deviation and improve abduction in these eyes is by transposition of vertical rectus muscles to the LR along the spiral of Tillaux..$^{99}$ This may or may not be combined with MR recession, as there is risk of inducing anterior segment ischemia. There is also a risk of inducing new vertical or torsional deviations in these eyes, the most common being a hypotropia. ${ }^{100}$ To prevent this, intraoperative FDT $^{96,97}$ meticulous dissection of the vertical rectus to release them from the lid retractors and intraoperative monitoring of torsion is recommended after FDT. ${ }^{101}$

In 2006, Johnston et al ${ }^{102}$ described the role of superior rectus transposition (SRT) to the LR with or without MR recession. In their analyses of 52 patients with type I esotropic DRS, the preoperative deviation (range: 10-30 PD) improved to within $10 \mathrm{PD}$ of esotropia in $95 \%$ of patients. Head turn improved in all cases, with complete elimination in $27 \%$ of the patients. Preoperative abduction limitation was noted to be from -3 to -4 in all eyes, which increased by $15^{\circ}-45^{\circ}$ after SRT. They also noted that there were no induced vertical deviations after SRT, unlike those seen after transposing both the vertical rectus muscles.

Mehendale et $\mathrm{al}^{103}$ further modified this procedure by enhancing SRT with an augmentation suture to the LR (8-12 $\mathrm{mm}$ from insertion) with or without adjustable MR recession. They found good postoperative alignment and improvement in abduction.

Thus, in esotropic DRS, SRT may be considered as an initial procedure when the primary position deviation is 12-14 PD or lesser. On intraoperative FDT, the point when abduction restriction can be felt is the amount of abduction that may recover from a transposition. For deviations larger than 15 PD, SRT may be combined with MR recession (Figure 3A and B) as described here. After performing MR recession which may be adjustable, a fornix conjunctival
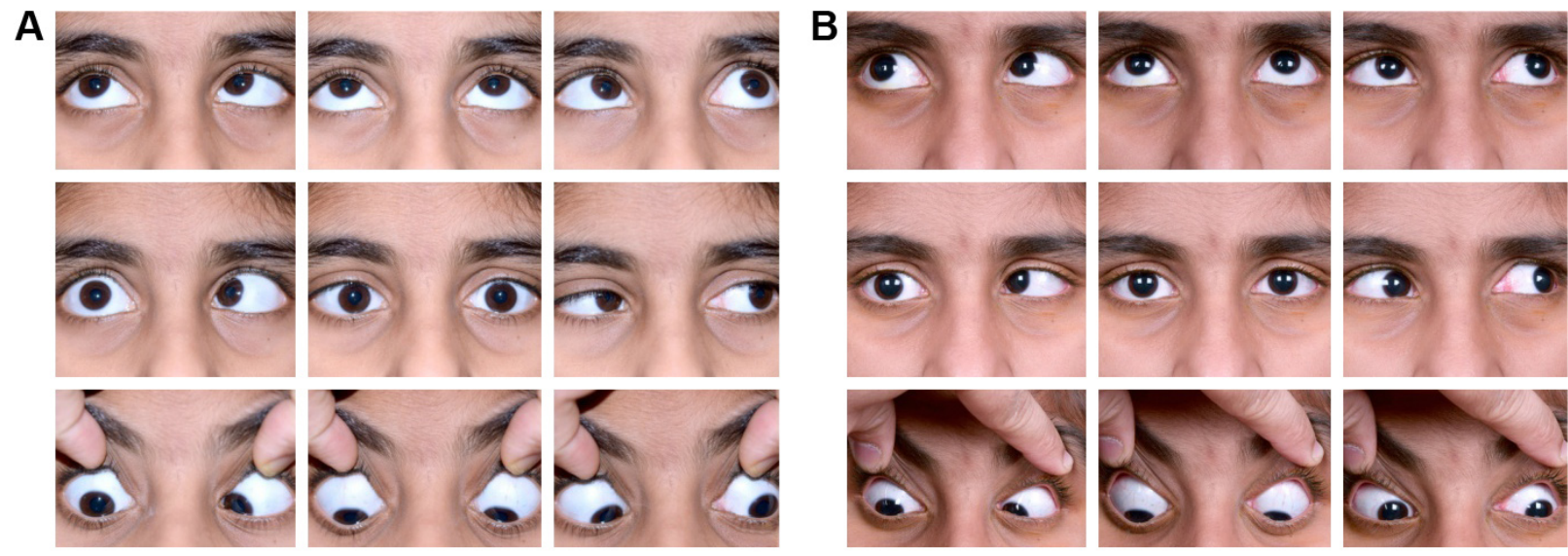

Figure 3 Outcome of medial rectus recession with superior rectus transposition in type I esotropic DRS.

Note: (A) Preoperative and (B) postoperative nine-gaze photograph following right medial rectus recession combined with superior rectus transposition. Abbreviation: DRS, Duane retraction syndrome. 
incision is made between the lateral border of superior rectus and the superior border of LR. Alternatively, a limbal peritomy extending up to 2 clock hours can be made in this quadrant. The superior rectus muscle is carefully dissected. The entire muscle belly and tendon is then transposed temporally to the LR, such that the temporal border of the superior rectus (SR) is $2 \mathrm{~mm}$ adjacent to the superior border of the LR, and the nasal border of the SR is reattached to the scleral following the spiral of Tillaux. The transposition is then augmented using a 5-0 nonabsorbable polyester suture through the sclera $8 \mathrm{~mm}$ posterior to the insertion of the LR, including the lateral thirds of each muscle. While augmented transpositions are practiced by the author, some surgeons describe the criteria for nonaugmented transpositions such as primary position deviation of less than or up to $18 \mathrm{PD}$ and head turn of $\leq 18^{\circ} .{ }^{104}$ Combining SRT with $\mathrm{MR}$ recession has been shown to be more effective than unilateral or bilateral MR recession in terms of improving abduction. Also, a combined procedure allows a smaller recession to improve both the deviation in the primary gaze and compensatory head posture. ${ }^{105}$ Thus, when esotropia is $>15$ PD, SRT along with unilateral or bilateral adjustable MR recession up to $5 \mathrm{~mm}$ can be planned based on the size of deviation and muscle tightness. ${ }^{106}$

In patients with residual esotropia after MR recession and SRT, another alternative is to add inferior rectus transposition. In those cases of residual esotropia who have undergone vertical rectus transposition and have a negative FDT, one needs to explore the transposed muscles to look for their migration, slippage or dragging of the augmentation suture. Patients may also develop consecutive exotropia following vertical rectus transposition (VRT) due to excess tightness by the VRT or a weak or excessively recessed MR. Late-onset exotropia may be explained by slipped MR, stretched scar or secondary LR tightness. If during resurgery, FDT is negative, then exotropia may be corrected with MR advancement and clearing any scar tissue. Moreover, in cases with negative FDT, the transposed muscles may need to be repositioned after releasing the augmentation suture. ${ }^{106}$

\section{Exotropic DRS}

Patients with exotropic DRS usually have type III DRS followed by type II, both of which may be commonly associated with globe retraction and overshoots. Cases with isolated unilateral exotropic DRS can be managed with unilateral LR recession if the deviation is within 20 PD, increasing the surgical dosage compared to the standard surgical dose. If larger deviations are noted, bilateral LR recession may be needed, which can be performed asymmetrically with larger recession in the contralateral eye. This may help prevent worsening of abduction limitation if present. ${ }^{101}$

Patients with type II exotropic DRS may have associated moderate to severe globe retraction, which can be managed with differential recessions of MR and LR in the affected eye. ${ }^{107}$

In DRS types II and III, supramaximal LR recession and LR periosteal fixation ${ }^{108}$ with or without vertical rectus transposition may also be done. Sharma et al, ${ }^{109}$ in their study, have explained that the paradoxical innervation of LR during adduction improves with recession or periosteal fixation, while the abduction can be improved by vertical rectus transposition. They concluded that LR periosteal fixation, with and without partial VRT is effective in exotropic DRS. In addition, they found that while both procedures equally corrected the exodeviation and anomalous head posture, the abduction limitation changed from -3.8 to -3.6 in the former vs from -3.6 to -2.8 in the latter.

Management of bilateral exotropic DRS needs to be planned depending upon the presenting type in either eye. Theodorou and Burke ${ }^{110}$ treated 11 patients with bilateral exotropic DRS. Unilateral LR recession (3-18 mm recessions for deviations ranging from 12 to $60 \mathrm{PD}$ ) with conjunctival recession was the commonest surgery done, and cases with significant globe retraction also underwent additional small $\mathrm{MR}$ recession.

In the experience of the senior author, symmetrical or asymmetrical bilateral LR recessions with or without Y splitting are more effectual for treating bilateral exotropic DRS. Synergistic divergence, which is an extreme form of exotropic DRS, is very challenging to treat, and no definite surgical procedure has been found with satisfactory outcomes. ${ }^{11}$

\section{Globe retraction}

As discussed in the previous section, globe retraction can be corrected with recessions of the co-contracting muscles. MR recession ranging from 5 to $6.5 \mathrm{~mm}$ and LR ranging from 7 to $9 \mathrm{~mm}$ or sometimes even periosteal fixation may be required. ${ }^{103}$ When primary position esotropia is present, MR should be recessed more than LR; if not, then LR can be recessed $1 \mathrm{~mm}$ more than MR. It has been suggested that adults may need larger recessions than pediatric patients due to long-standing globe retraction causing orbital tissue changes, and retraction may recur due to continued cocontraction of the muscles. ${ }^{112}$ 


\section{Overshoots}

Upshoots and downshoots in DRS may be due to the mechanical effect caused by tight muscles or due to innervational anomalies. Rogers and Bremmer ${ }^{113}$ have described Y splitting of the LR with or without its recession to treat overshoots caused by this mechanical leash effect. With Y split, each muscle half balances the other; thus, when the eye elevates in adduction, the lower arm contracts and prevents the globe from suddenly slipping up and vice versa in depression.

Awadein ${ }^{114}$ studied the role of inferior oblique (IO) weakening in all types of DRS which presented with a slow upshoot in which the movement was similar to IO overaction. He found that IO myectomy with or without horizontal rectus recession improved upshoot in this set of patients without inducing any vertical deviations or IO underaction.

\section{Approach to the patient: an overview}

The above review emphasizes the need to extend patient evaluation in cases of DRS beyond the routine clinical examination by a strabismologist to genetic analysis, systemic workup and neuroimaging. The understanding of DRS as a part of CCDD spectrum has evolved over time with identification of various genetic mutations as the underlying cause of these disorders. Also, phenotypic variability has been established among individuals with heterozygous CHN1 mutations, even with vertical deviations in the absence of DRS. Hence, patients with bilateral DRS with associated vertical anomalies and those with familial vertical deviations should undergo a detailed pedigree assessment and genetic screening for CHN1 mutations. Members of families with DRS as an autosomal dominant trait should be screened for mutations in the CHNI gene, enhancing genetic counseling and permitting earlier diagnosis. Mutations such as SALL4, SALL1 and those involving chromosomes 8 and 22 are often associated with syndromic DRS; hence, a complete systemic evaluation including $\mathrm{X}$-ray spine, renal function tests and audiometry is mandated, if these mutations are tested positive. ${ }^{80}$ Common among these is the presence of unilateral or bilateral sensorineural deafness, as found by Kirkham ${ }^{81}$ in $11 \%$ of 112 patients with DRS in his case series, and he has recommended a detailed family history and audiologic examination for all cases of DRS. Especially, the presence of neck anomalies should warn the clinician of underlying hearing loss to be likely due to Wildervanck syndrome, and an auditory evaluation should be done. MRI would be ideal in all cases of DRS, as a variable endophenotype has been noted by Demer et al. Though they found abnormal abducens nerve or LR muscle most commonly, superior oblique hypoplasia was noted in half of the tested individuals, suggesting involvement of the fourth cranial nerve in these cases. The only muscles that were not affected were those supplied by the inferior division of the oculomotor nerve: the inferior rectus, MR and IO muscles. ${ }^{115}$ Thus, a combination of ocular and, when necessary, systemic evaluation, pedigree analysis, MRI and gene product characterization will help in better understanding the clinical presentation and to provide better care to DRS patients and their families.

\section{Conclusion}

DRS consists of a complex set of ocular and systemic anomalies, which may have myriad presentations. It is caused by mechanical, innervational, genetic, embryologic and central nervous system anomalies occurring together or as an independent etiology.

Management of DRS is a challenge, and the surgical approach to such a patient must be individualized based on the amount of ocular deviation, abnormal head position, associated globe retraction and overshoots.

\section{Acknowledgment}

The photography team of LVPEI is gratefully acknowledged. The parents or guardians of the patients gave consent for their images to be used in this paper.

\section{Author contributions}

Both authors contributed toward data analysis, drafting and critically revising the paper and agree to be accountable for all aspects of the work.

\section{Disclosure}

The authors report no conflicts of interest in this work.

\section{References}

1. Duane A. Congenital deficiency of abduction associated with impairment of adduction, retraction movements, contraction of the palpebral fissure and oblique movements of the eye. Arch Ophthalmol. 1996;114(10) $1255-1256$

2. DeRespinis P, Caputo A, Wagner R, Guo S. Duane's retraction syndrome Surv Ophthalmol. 1993;38(3):257-288.

3. Gurwoods AS, Terrigno CA. Duane's retraction syndrome: literature review. Optometry. 2000;71(11):722-776.

4. Heuck G. Uber angeborenene vererbten Beweglichkeitsdefect der Augen. Klin Monatsbl Augenkeilkd. 1879;17:253.

5. Sinclair WW. Abnormal associated movements of the eyelids. Ophthalmol Rev. $1895 ; 14: 307$

6. Bahr K. Vorstellung eines Falles von eigenartiger Muskelanomalie eines Auges Ber Dtsch. Ges Opthalmol. 1896;25:334.

7. Stilling J, Bergmann JF, editors. Untersuchungen uber die Entstehung der Kurzsichtigkeit. Wiesbaden, Germany; 1887:13.

8. Turk S. Bemerkungen zu einem Falle von Retraction des Auges. Cbl Pract Augenheilk. 1899;23:14. 
9. Wolff J. The occurrences of retraction movements of the eyeball together with congenital defects in the external ocular muscles. Arch Ophthalmol. 1900;29:297.

10. Gallus E. Sinddiesog angeborener: Retraktionsberegungen des Auges die Folge einer Gebutsverletzurg. Arch Augenheilkd. 1921;87: $35-45$.

11. Axenfeld TH, Schurenberg E. Angeborene Retractionsbewegungen. Klin Monats. 1901;39:851.

12. Breinin GM. In discussion of: de Gindersen T, Zeavin B. Observations on the retraction syndrome of Duane. Arch Ophthalmol. 1956;55:576.

13. Zauberman H, Magora A, Chaco J. An electromyographic evaluation of the retraction syndrome. Am J Ophthalmol. 1967;64(6):1103-1108.

14. Sato S. Electromyographic study on retraction syndrome. Jpn J Ophthalmol. 1960;4:57-66.

15. Strachan IM, Brown BH. Electromyography of extraocular muscles in Duane's syndrome. Br J Ophthalmol. 1972;56(8):594-599.

16. Metz HS. The diagnosis and treatment of abduction deficiencies. Ann Ophthalmol. 1976;8(6):683-693.

17. Miller NR, Kiel SM, Green WR, Clark AW. Unilateral Duane's retraction syndrome (type 1). Arch Ophthalmol. 1982;100(9): $1468-1472$

18. Hotchkiss MG, Miller NR, Clark AW, Green WR. Bilateral Duane's syndrome. Arch Ophthalmol. 1980;98(5):870-874.

19. Hoyt WF, Nachtigaller H. Anomalies of ocular motor nerves. Am J Ophthalmol. 1965;60(3):443-448.

20. Ramsay J, Taylor D. Congenital crocodile tears: a key to the etiology of Duane's syndrome. Br J Ophthalmol. 1980;64(7):518-522.

21. Schmidt D. Congenitale Augenmuskelparesen. Albrech v Graefes Arch Ophthalmol. 1974;192(4):285.

22. Parsa CF, Grant E, Dillon WP, du Lac S, Hoyt WF. Absence of the abducens nerve in Duane syndrome verified by magnetic resonance imaging. Am J Ophthalmol. 1998;125(3):399-401.

23. Assaf AA. Congenital innervation dysgenesis syndrome (CID)/congenital cranial dysinnervation disorders (CCDDs). Eye. 2011;25(10): 1251-1261.

24. Gutowski NJ, Ellard S. The congenital cranial dysinnervation disorders (CCDDs). Adv Clin Neurosci Rehabil. 2005;5:8-10.

25. Nakano M, Yamada K, Fain J, et al. Homozygous mutations in ARIX(PHOX2A) result in congenital fibrosis of the extraocular muscles type 2. Nat Genet. 2001;29(3):315-320.

26. Tischfield MA, Bosley TM, Salih MA, et al. Homozygous HOXA1 mutations disrupt human brainstem, inner ear, cardiovascular and cognitive development. Nat Genet. 2005;37(10):1035-1037.

27. Jen IC, Chan WM, Bosley TM, et al. Mutations in a human ROBO gene disrupt hindbrain axon pathway crossing and morphogenesis. Science. 2004;304(5676):1509-1513.

28. Oystreck DT, Engle EC, Bosley TM. Recent progress in understanding congenital cranial dysinnervation disorders. J Neuroophthal. 2011; 31(1):69-77.

29. Miyake N, Chilton J, Psatha M, et al. Human CHN1 mutations hyperactivate a2-chimaerin and cause Duane's retraction syndrome. Science. 2008;321(5890):839-843.

30. Appukuttan B, Gillanders E, Juo SH, et al. Localization of a gene for Duane retraction syndrome to chromosome 2q31. Am J Hum Genet. 1999; 65(6):1639-1646.

31. Al-Baradie R, Yamada K, St Hilaire C, et al. Duane radial ray syndrome (Okihiro syndrome) maps to $20 \mathrm{q} 13$ and results from mutations in SALL4, a new member of the SAL family. Am J Hum Genet. 2002;71(5): 1195-1199

32. Kohlhase J, Heinrich M, Schubert L, et al. Okihiro syndrome is caused by SALL4 mutations. Hum Mol Genet. 2002;11(23):2979-2987.

33. Kohlhase J, Schubert L, Liebers M, et al. Mutations at the SALL4 locus on chromosome 20 result in a range of clinically overlapping phenotypes, including Okihiro syndrome, Holt-Oram syndrome, acro-renalocular syndrome, and patients previously reported to represent thalidomide embryopathy. J Med Genet. 2003;40(7): $473-478$.
34. Mehdorn E, Kommerell G. Inherited Duane's syndrome. Mirrorlike localization of oculomotor disturbances in monozygotic twins. J Pediatr Ophthalmol Strabismus. 1979;16:152.

35. Pfaffenbach DD, Cross HE, Kearns TP. Congenital anomalies in Duane's retraction syndrome. Arch Ophthalmol. 1972;88:635-639.

36. Miller MT, Strömland KK. What can we learn from the thalidomide experience: an ophthalmologic perspective. Curr Opin Ophthalmol. 2011; 22(5):356-3664.

37. Gobin MH. Surgical management of Duane's syndrome. Br J Ophthalmol. 1974;58(3):301-306.

38. Miller NR, Kiel SM, Green WR, et al. Unilateral Duane's retraction syndrome (Type 1). Arch Ophthalmol. 1982;100(9):1468-1472.

39. von Noorden GK, Murray E. Up- and downshoots in Duane's retraction syndrome. J Pediatr Ophthalmol Strabismus. 1986;23:212-215.

40. Jampolsky A. Surgical leashes and reverse leashes in strabismus surgical management. In: Symposium on Strabismus. Transactions of the New Orleans Academy of Ophthalmology. St Louis, MO: CV Mosby; 1978:244-268.

41. Papst W. Klin Monbl Augenheilkd Augenarztl Fortbild. [Motility disorders of the eye due to paradoxical innervation]. Klin Monatsbl Augenheilkd. 1962;141:199-209. German.

42. Papst W, Esslen E. Symptomatology and therapy of ocular motility disturbances. Am J Ophthalmol. 1964;58:275-291.

43. Papst W. Paralytischer Strabismus infolge paradoxer innervation. Ber Dstch Ophthalmol Ges. 1966;67:84.

44. Malbran J. Estrabismos y paralysis. Clinica y terapeutua Buenos Anes, Editorial Oftalmologia. 1949;625.

45. Lyle TK, Bridgeman GJO. Worth and Chavasse's Squint. The Binocular Reflexes and the Treatment of Strabismus. 9th ed. London: Bailliere Tindall and Cox; 1959:251-255.

46. Huber A. Electrophysiology of the retraction syndromes. $\mathrm{Br} \mathrm{J}$ Ophthalmol. 1974;58(3):293-300.

47. Ahluwalia BK, Gupta NC, Goel SR, Khurana AK. Study of Duane's retraction syndrome. Acta Ophthalmologica. 1988;66(6):728-730.

48. Kirkham TH. Inheritance of Duane's syndrome. Br J Ophthalmol. 1970; 54(5):323-329

49. Moster M. Paresis of Isolated and Multiple Cranial Nerves and Painful Ophthalmoplegia. In: Yanoff M, Duker JS, editors. Ophthalmology. Philadelphia, PA: Mosby; 1999

50. Kekunnaya R, Gupta A, Sachdeva V, et al. Duane retraction syndrome: series of 441 cases. J Pediatr Ophthalmol Strabismus. 2012;49(3):164-169.

51. Mohan K, Sharma A, Pandav SS. Differences in epidemiological and clinical characteristics between various types of Duane retraction syndrome in 331 patients. J AAPOS. 2008;12(6):576-580.

52. Khan AO, Oystreck DT. Clinical characteristics of bilateral Duane syndrome. J AAPOS. 2006;10(3):198-201.

53. Khan AO, Oystreck DT, Wilken K, Akbar F. Duane retraction syndrome on the Arabian peninsula. Strabismus. 2007;15(4):205-208.

54. Tredici TD, von Noorden GK. Are anisometropia and amblyopia common in Duane's syndrome? J Pediatr Ophthalmol Strabismus. 1985;22:23-25.

55. O’Malley ER, Helveston EM, Ellis FD. Duane's retraction syndromeplus. J Pediatr Ophthalmol Strabismus. 1982;19(3):161-165.

56. Parsa CF, Robert MP. Thromboembolism and congenital malformations: from Duane syndrome to thalidomide embryopathy. JAMA Ophthalmol. 2013;131(4):439-447.

57. Miyake N, Demer JL, Shaaban S, et al. Expansion of the CHN1 strabismus phenotype. Invest Ophthalmol Vis Sci. 2011;52(9):6321-6328.

58. Souza-Diaz C. Congenital VI nerve palsy is Duane's syndrome until disproven (letter). Binocular Vision Ocular Motility. 1992;7:70.

59. Hering E. In: Die Lehre vom Binoculren Sehen. Leipzig, Germany: Wilhelm Englemann; 1868.

60. Kekunnaya R, Velez FG, Pineles SL. Outcomes in patients with esotropic duane retraction syndrome and a partially accommodative component. Indian J Ophthalmol. 2013;61(12):701-704.

61. Kirkham TH. Anisometropia and amblyopia in Duane's syndrome. Am J Ophthalmol. 1970;69:774-777. 
62. Hugonnier R, Clayette-Huggonier S. Strabismus, heterophoria, ocular motor paralysis. In: S Veronnean-Troutman, editor. Clinical Ocular Muscle Imbalance. St Louis, MO: CV Mosby; 1969:322-327.

63. Isenberg S, Urist MJ. Clinical observations in 101 consecutive patients with Duane's retraction syndrome. Am J Ophthalmol. 1977;84(3):419-425.

64. Ro A, Gummeson B, Orton RB, Cadera W. Duane's retraction syndrome: southwestern ontario experience. Can J Ophthalmol. 1989; 24(5):200-203.

65. Chung M, Stout JT, Borchert MS. Clinical diversity of hereditary Duane's retraction syndrome. Ophthalmology. 2000;107(3):500-503.

66. Mohan K, Saroha V, Sharma A. Factors predicting upshoots and downshoots in Duane's retraction syndrome. J Pediatr Ophthalmol Strabismus. 2003;40(3):147-151.

67. Kekunnaya R, Moharana R, Tibrewal S, Patil PC, Sachdeva V. A simple and novel grading method for retraction and overshoot in Duane retraction syndrome. Br J Ophthalmol. 2016;100:1451-1454.

68. Raab EL. Clinical features of Duane's syndrome. J Pediatr Ophthalmol Strabismus. 1986;23:64-68.

69. Maruo TK, Arimoto N, Kikuchi R. Duane's syndrome. Jpn J Ophthalmol. 1979;23:453-468.

70. Zanin E, Gambarelli N, Denis D. Distinctive clinical features of bilateral Duane retraction syndrome. J AAPOS. 2010;14(4):293-297.

71. Jampolsky A. Duane Syndrome. In: Rosenbaum AC, Santiago AP, editors. CSM, Principles and Surgical Techniques. Philadelphia, PA: W.B. Saunders; 1999:325-346.

72. Wildervanck LS. Een geval van aandoening van Klippel-Feil Gecombineerd met Abducensparalyse, retractio bulbi en Doofstomheid. Ned T Geneesk. 1952;96:2752-2755.

73. Wilcox LM, Gittinger JW, Breinin GM. Congenital adduction palsy and synergistic divergence. Am J Ophthalmol. 1981;91:1-7.

74. Metz HS. Duane's retraction syndrome and severe adduction deficiency dettery. Arch Ophthalmol. 1986;104:1586-1587.

75. Mittal V, Gupta A, Sachdeva V, Kekunnaya R. Duane retraction syndrome with posterior microphthalmos: a rare association. J Pediatr Ophthalmol Strabismus. 2012;49:E48-E51.

76. Weiss IS, Urist MJ. Duane's syndrome associated with tendon sheath syndrome and microcornea. J Pediatr Ophthalmol Strabismus. 1972;9(1):14-15.

77. Cibis GW. Congenital familial external ophthalmoplegia with co-contraction. Ophthalmic Paediatr Genetics. 1984;4:163-168.

78. Collins ET. Enophthalmos. Br Med J. 1899;2:846-851.

79. Yang MM, Ho M, Lau HH, et al. Diversified clinical presentations associated with a novel sal-like 4 gene mutation in a Chinese pedigree with Duane retraction syndrome. Mol Vis. 2013;19:986-994.

80. Graeber CP, Hunter DG, Engle EC. The genetic basis of incomitant strabismus: consolidation of the current knowledge of the genetic foundations of disease. Semin Ophthalmol. 2013;28(5-6):427-437.

81. Kirkham TH. Duane's syndrome and familial perceptive deafness. Br J Ophthalmol. 1969;53:335-339.

82. Duane TD, Schatz NJ, Caputo AR. Pseudo-Duane's retraction syndrome. Trans Am Ophthalmol Soc. 1976;74:122-129.

83. Gittinger JW Jr, Hughes JP, Suran EL. Medial orbital wall blow-out fracture producing an acquired retraction syndrome. JClin Neuroophthalmol. 1986;6(3):153-156.

84. Kivlin JD, Lunderman MK. Acquired Retraction syndrome associated with orbital metastasis. J Pediatr Ophthalmol Strabismus. 1985; 22(3):109-112.

85. Kargi SH, Atasoy HT, Sayarlioglu H, Koksal M, Ugurbas HS, Alpay A. Acquired retraction of the eye as the first sign of myositis. Strabismus. 2005;13(2):85-88.

86. Sood GC, Srinath BS, Krishnamurthy G. Acquired Duane's retraction syndrome following Kronlein's operation. Eye Ear Nose Throat Mon. 1975;54(8):308-310

87. Khan AO. Inverse globe retraction syndrome complicating recurrent pterygium. Br J Ophthalmol. 2005;89(5):640-641.

88. Smith JL, Damast M. Acquired retraction syndrome after sixth nerve palsy. Br J Ophthalmol. 1973;57(2):110-114.
89. Akiko Y, Masato W, Tetsuro T, Keichi G. Bilateral Duane’s retraction syndrome due to large pontine glioma. Neuro Ophthalmol Japan. 2003;20(1):66-70.

90. Yüksel D, Orban de Xivry J, Lefèvre P. Review of the major findings about Duane retraction syndrome (DRS) leading to an updated form of classification. Vision Res. 2010;50(23):2334-2347.

91. Silverberg M, Demer J. Duane's syndrome with compressive denervation of the lateral rectus muscle. Am J Ophthalmol. 2001;131(1): $146-148$

92. Varma C, Aroor S, Mundkur SC, Annamalai K. Bilateral type-I duane syndrome with multiple anamolies: a case report. J Clin Diagn Res. 2012;6(8):1435-1436.

93. Amaral D, Dawson G, Geschwind D. Autism Spectrum Disorders. Oxford: Oxford University Press; 2011:866.

94. Kraft SP. Surgery for Duane's syndrome. Am Orthoptic J. 1993; 43:18-26.

95. Kaban TJ, Smith K, Day C, et al. Single medial rectus recession in unilateral Duane syndrome type I. Am Orthoptic J. 1995;45:108-114.

96. Kraft SP. A surgical approach for Duane syndrome. J Pediatr Ophthalmol Strabismus. 1988;25(3):119-130.

97. Kraft SP. Resecting the lateral rectus in unilateral Duane syndrome with esotropia and limited abduction. Binoc Vis Strab Q. 2010;25(3): 149-157.

98. Sachdeva V, Kekunnaya R, Gupta A, Bhoompally VR. Surgical management of bilateral esotropic Duane syndrome. J AAPOS. 2012; 16(5):445-448.

99. Rosenbaum AL. Costenbader Lecture. The efficacy of rectus muscle transposition surgery in esotropic Duane syndrome and VI nerve palsy. J AAPOS. 2004;8(5):409-419.

100. Ruth A, Velez FG, Rosenbaum AL. Management of vertical deviations after vertical rectus transposition surgery. J AAPOS. 2009;13(1):16-19.

101. Holmes JM, Hatt SR, Leske DA. Intraoperative monitoring of torsion to prevent vertical deviations during augmented vertical rectus transposition surgery. J AAPOS. 2012;16(2):136-140.

102. Johnston SC, Crouch ER Jr, Crouch ER. An innovative approach to transposition surgery is effective in treatment of Duane's syndrome with esotropia. Invest Ophthalmol Vis Sci. 2006;47:2475.

103. Mehendale RA, Dagi LR, Wu C, Ledoux D, Johnston S, Hunter DG. Superior rectus transposition and medial rectus recession for Duane syndrome and sixth nerve palsy. Arch Ophthalmol. 2012;130(2): 195-201.

104. Velez F, Foster R, Rosenbaum A. Vertical rectus muscle augmented transposition in Duane syndrome. J AAPOS. 2001;5(2):105-113.

105. Yang S, MacKinnon S, Dagi LR, Hunter DG. Superior rectus transposition vs medial rectus recession for treatment of esotropic Duane syndrome. JAMA Ophthalmol. 2014;132(6):669-675.

106. Kekunnaya R, Kraft R, Rao VB, Velez FG, Sachdeva V, Hunter DG. Surgical management of strabismus in Duane retraction syndrome. J AAPOS. 2015;19(1):63-69.

107. Sprunger DT. Recession of both horizontal rectus muscles in Duane syndrome with globe retraction in primary position. J AAPOS. 1997; 1(1):31-33.

108. Velez FG, Thacker N, Britt MT, Alcorn D, Foster RS, Rosenbaum AL. Rectus muscle orbital wall fixation: a reversible profound weakening procedure. J AAPOS. 2004;8(5):473-480.

109. Sharma P, Tomer R, Menon V, Saxena R, Sharma A. Evaluation of periosteal fixation of lateral rectus and partial VRT for cases of exotropic Duane retraction syndrome. Indian J Ophthalmol. 2014;62(2): 204-208

110. Theodorou N, Burke J. Surgical and functional outcomes in bilateral exotropic Duane's retraction syndrome. Br J Ophthalmol. 2013;97(9): 1134-1137.

111. Khawam E, Terro A, Hamadeh I. Surgical correction of synergistic divergence strabismus. A report of three cases. Binocul Vis Strabismus Q. 2007;22(4):227-234.

112. Shauly Y, Weissman A, Meyer E. Ocular and systemic characteristics of Duane syndrome. J Pediatr Ophthalmol Strabismus. 1993;30:178-183. 
113. Rogers GL, Bremmer DL. Surgical treatment of the up-shoot and down-shoot in Duane's retraction syndrome. Ophthalmology. 1984; 91(11):1380-1382.

114. Awadein A. Inferior oblique myectomy for upshoots mimicking inferior oblique overaction in Duane retraction syndrome. J AAPOS. 2013;17(3):253-258.
115. Demer JL, Clark RA, Lim KH, Engle EC. Magnetic resonance imaging evidence for widespread orbital dysinnervation in dominant Duane's retraction syndrome linked to the DURS2 locus. Invest Ophthalmol Vis Sci. 2007;48(1):194-202.

\section{Publish your work in this journal}

Clinical Ophthalmology is an international, peer-reviewed journal covering all subspecialties within ophthalmology. Key topics include: Optometry; Visual science; Pharmacology and drug therapy in eye diseases; Basic Sciences; Primary and Secondary eye care; Patient Safety and Quality of Care Improvements. This journal is indexed on

\section{Dovepress}

PubMed Central and CAS, and is the official journal of The Society of Clinical Ophthalmology (SCO). The manuscript management system is completely online and includes a very quick and fair peer-review system, which is all easy to use. Visit http://www.dovepress.com/ testimonials.php to read real quotes from published authors. 